\title{
Evaluation of Antibiotic Use Among Sepsis Patients in an Intensive Care Unit A cross-sectional study at a referral hospital in Indonesia
}

"Ratna S. Dewi, ${ }^{1}$ Maksum Radji, ${ }^{2}$ Rizka Andalusia ${ }^{3}$

$$
\text { تقييم استخدام المضادات الحيوية عند المصابين بالإنتان في وحلدة عناية مركزة }
$$

$$
\text { راتنا ساري دووي، ماكسوم رادجي، رزقا أندلوسيا }
$$

ABSTRACT: Objectives: This study aimed to evaluate the appropriateness of antibiotic use and factors associated with outcomes among sepsis patients in an intensive care unit (ICU). Methods: This cross-sectional study was carried out from February to May 2017 and included all adult patients with sepsis or septic shock admitted to the ICU of Dharmais Cancer Hospital, Jakarta, Indonesia. Data were collected from the patients' medical records. Results: A total of 60 patients with sepsis or septic shock were admitted to the ICU during the study period. The most common source of infection was hospital-acquired pneumonia (61.7\%) and the majority had two or more comorbidities (93.3\%). There were 115 antibiotic regimens prescribed. Overall, 33.3\% of patients were prescribed inappropriate types of antibiotics and $51.7 \%$ were given an inappropriate dosage. The mortality rate was $68.3 \%$. There was a statistically significant association between patient outcome and inappropriate doses of antibiotics $(P=0.034)$, although not inappropriate types of antibiotics $(P=0.050)$. A multivariate analysis indicated that the main factors influencing patient outcome were septic shock and the presence of at least two comorbidities $(P<0.050$ each). Conclusion: Inappropriate doses of antibiotics, a diagnosis of septic shock and the presence of at least two comorbidities were found to significantly increase the mortality rate of sepsis patients admitted to an ICU in Indonesia.

Keywords: Drug Prescription, trends; Antibiotics; Sepsis; Septic Shock; Intensive Care Units; Indonesia.

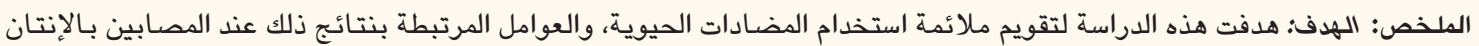

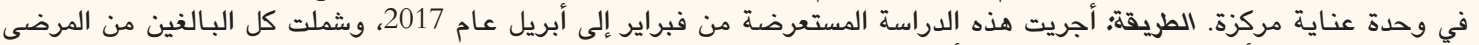

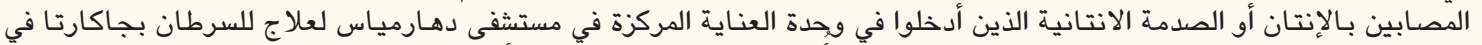

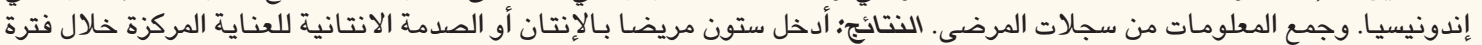

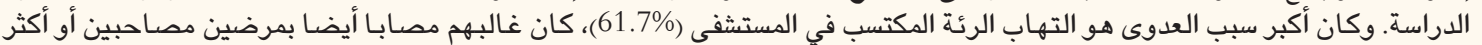

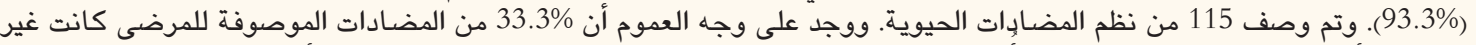

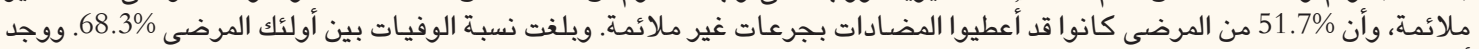

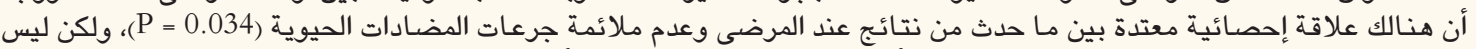

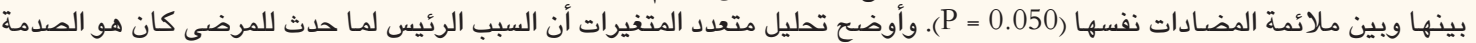

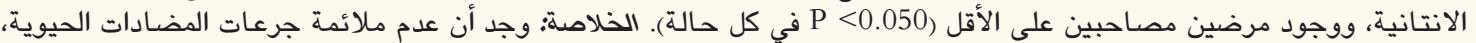

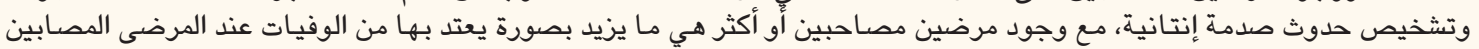

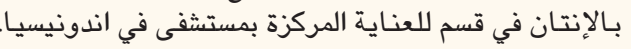

$$
\text { الكلمات المفتاحية: وصفات الأدوية، اتجاهـات؛ مضادات حيوية؛ إنتان؛ صدمة إنتانية؛ وحدة عناية مركزة؛ إندونيسيا. }
$$

\section{ADVANCES IN KNOWLEDGE}

This study found that the mortality rate of sepsis patients admitted to an intensive care unit in Indonesia was quite high.

Factors found to significantly influence mortality included inappropriate doses of antibiotics, a diagnosis of septic shock and the presence of at least two comorbidities.

\section{Application to Patient Care}

The results of this study could be used by physicians, pharmacists and other healthcare workers to increase the appropriate use of antibiotics, perhaps by implementing an antibiotic stewardship programme or with the formulation of guidelines for appropriate antibiotic usage based on the source of infection and the patient's clinical condition.

$\mathrm{S}$ EPSIS IS A LIFE-THREATENING CONDITION CAUSED by a dysregulated host response to infection leading to organ dysfunction. ${ }^{1}$ It is most likely to develop in individuals with a weakened immune system, often because of treatments such as chemotherapy. However, critically-ill patients are also at risk due to the prevalence of drug-resistant bacteria in hospital settings and the need for catheterisation and wound drainage. ${ }^{2}$ Sepsis 
occurs in approximately $2 \%$ of all hospitalised cases and among $6-30 \%$ of all patients admitted to intensive care units (ICUs) in developed countries. ${ }^{3,4}$ Both sepsis and septic shock are leading causes of morbidity and mortality in ICUs (21\% and $28 \%$, respectively). ${ }^{4-6}$

The management of sepsis or septic shock requires a comprehensive and systematic approach combining the use of appropriate diagnostic measures, the rapid initiation of appropriate empirical antibiotics and the administration of supportive therapy. ${ }^{7}$ According to international guidelines for the management of sepsis and septic shock, appropriate antimicrobials should be administered within one hour of diagnosis, with the dosage optimised according to standard pharmacokinetic/pharmacodynamic principles. ${ }^{8}$ In addition, the patient's location at the time of infection, the source of the infection and the prevalence and susceptibility patterns of common local pathogens should also be factored into the choice of therapy. ${ }^{8,9}$

In ICUs, antibiotics are the most common type of medicine and are prescribed approximately 10 times more than in general hospital wards. ${ }^{10}$ However, inappropriate therapy and delays in prescribing appropriate antibiotics are important factors related to increased morbidity and mortality in sepsis patients. ${ }^{8,11,12}$ In Thailand, there were 229 cases of sepsis reported in 2012, of which 61.6\% developed septic shock; the overall mortality rate for patients who were prescribed first-dose inappropriate and appropriate antibiotics was $75 \%$ and $68.3 \%$, respectively. ${ }^{13}$ In a referral hospital in Indonesia, there were 126 cases of sepsis admitted between 2011 and 2012; the mortality rate was $81.8 \%$ and $66.7 \%$, respectively, for patients prescribed inappropriate types and doses of antibiotics. ${ }^{14}$

The Dharmais Cancer Hospital is a 364-bed tertiary care hospital in Jakarta, Indonesia, which also serves as a cancer referral centre. According to a retrospective study, $18.5 \%$ of patients admitted to this hospital between 2011 and 2012 had sepsis. 'However, to the best of the authors' knowledge, no studies have yet evaluated the appropriateness of antibiotic usage for sepsis patients in the hospital's ICU. This study therefore aimed to evaluate the appropriateness of antibiotic use with regards to antibiotic type and dosage and factors associated with patient outcomes among ICU patients with sepsis or septic shock admitted to Dharmais Cancer Hospital.

\section{Methods}

This cross-sectional study was carried out between February and May 2017 in the ICU of Dharmais Cancer Hospital. All adult sepsis or septic shock patients who were receiving antibiotic therapy and were hospitalised in the ICU for at least 24 hours during the study period were included. Patients with incomplete medical records,
Table 1: Recommended antibiotic regimen in sepsis cases according to source of infection ${ }^{17-20}$

\begin{tabular}{|c|c|}
\hline $\begin{array}{l}\text { Source of } \\
\text { infection }\end{array}$ & Recommended antibiotic regimen \\
\hline \multicolumn{2}{|l|}{ Pulmonary } \\
\hline \multirow[t]{2}{*}{ CAP } & $\begin{array}{l}\text { - } \beta \text {-lactam (i.e. ceftriaxone, cefotaxime or } \\
\text { ampicillin/sulbactam) plus azithromycin }\end{array}$ \\
\hline & $\begin{array}{l}\text { - } \beta \text {-lactam (i.e. ceftriaxone, cefotaxime } \\
\text { or ampicillin/sulbactam) plus respiratory } \\
\text { flouroquinolones (i.e. levofloxacin or } \\
\text { moxifloxacin) }\end{array}$ \\
\hline $\begin{array}{l}\text { HAP, HCAP } \\
\text { or VAP }\end{array}$ & $\begin{array}{l}\text { - Antipseudomonal } \beta \text {-lactam (i.e. piperacillin/ } \\
\text { tazobactam, cefepime, meropenem, imipenem } \\
\text { or doripenem) plus aminoglycosides (i.e. } \\
\text { gentamicin, tobramycin or amikacin) or } \\
\text { antipseudomonal flouroquinolone (i.e. } \\
\text { levofloxacin or ciprofloxacin)* }\end{array}$ \\
\hline \multicolumn{2}{|l|}{ Blood stream } \\
\hline CRBSI & $\begin{array}{l}\text { - Vancomycin or daptomycin }{ }^{\dagger} \text { plus } \\
\text { antipseudomonal } \beta \text {-lactam (i.e piperacillin/ } \\
\text { tazobactam and cefepime) or carbapenem (i.e. } \\
\text { meropenem, imipenem or doripenem) with } \\
\text { or without an aminoglycoside (i.e. gentamicin, } \\
\text { tobramycin or amikacin) }\end{array}$ \\
\hline
\end{tabular}

Urinary

Urosepsis - Third-generation cephalosporin (ceftriaxone or cefotaxime) with or without an aminoglycoside (gentamicin, tobramycin or amikacin) or fluoroquinolone (levofloxacin or ciprofloxacin)

Urological Antipseudomonal $\beta$-lactam (i.e piperacillin/ interventions tazobactam and cefepime) or carbapenem (i.e. meropenem, imipenem or doripenem $)^{\ddagger}$

Unknown

Unspecified Antipseudomonal $\beta$-lactam (i.e piperacillin/ tazobactam and cefepime) or carbapenem (i.e. meropenem, imipenem or doripenem) plus an aminoglycoside or antipseudomona flouroquinolon (i.e. levofloxacin or ciprofloxacin) plus vancomycin

$C A P=$ community-acquired pneumonia $; H A P=$ hospital-acquired pneumonia; HCAP = healthcare-associated pneumonia VAP = ventilator-associated pneumonia; $C R B S I=$ catheter-related blood-stream infection

*Vancomycin or linezolid can be added if methicillin-resistant Staphylococcus aureus is suspected. 'If there is a high rate of resistance to vancomycin (minimum inhibitory concentration of $\geq 2 \mu \mathrm{g} / \mathrm{mL}$ ). ${ }^{\neq}$This regimen is also recommended if there is a risk of multidrug resistance.

those who had subsequent episodes of sepsis/septic shock or who were admitted for less than 24 hours and those who were under 18 years of age were excluded. In addition, patients readmitted to the ICU during the study period were not evaluated again. The required sample size was calculated using the following formula: ${ }^{15}$

$$
\mathrm{n}=\frac{\left(Z_{1-\frac{\boldsymbol{\alpha}}{2}}^{2}\right) P(1-P)}{d^{2}}
$$

where $Z_{1-\frac{\alpha}{2}}$ is 1.96 (at a 95\% confidence interval), $P$ is $10 \%$ (the expected proportion of sepsis) and $d$ is 0.1 (the relative precision). ${ }^{15,16}$ Therefore, the total sample size required was 35 patients. 
Table 2: Characteristics of sepsis patients admitted to the intensive care unit of Dharmais Cancer Hospital, Jakarta, Indonesia $(\mathrm{N}=60)$

\begin{tabular}{|c|c|}
\hline Characteristic & n (\%) \\
\hline \multicolumn{2}{|l|}{ Age in years } \\
\hline $18-39$ & $9(15)$ \\
\hline $40-59$ & $39(65)$ \\
\hline$\geq 60$ & $12(20)$ \\
\hline Mean \pm SD (range) & $51.4 \pm 11.7(24-82)$ \\
\hline \multicolumn{2}{|l|}{ Gender } \\
\hline Male & $32(53.3)$ \\
\hline Female & $28(46.7)$ \\
\hline \multicolumn{2}{|l|}{ Diagnosis } \\
\hline Sepsis & $31(51.7)$ \\
\hline Septic shock & $29(48.3)$ \\
\hline \multicolumn{2}{|l|}{ Length of stay in days } \\
\hline$\geq 7$ & $12(20)$ \\
\hline$<7$ & $48(80)$ \\
\hline Median \pm SD (range) & $4.0 \pm 4.4(2-23)$ \\
\hline \multicolumn{2}{|l|}{ Ventilation use } \\
\hline Yes & $52(86.7)$ \\
\hline No & $8(13.3)$ \\
\hline \multicolumn{2}{|l|}{ SOFA score } \\
\hline$>8$ & $29(48.3)$ \\
\hline$\leq 8$ & $31(51.7)$ \\
\hline \multicolumn{2}{|l|}{ Source of infection } \\
\hline HAP & $37(61.7)$ \\
\hline IAI & $11(18.3)$ \\
\hline CAP & $3(5)$ \\
\hline UTI & $2(3.3)$ \\
\hline HCAP & $1(1.7)$ \\
\hline Unknown & $6(10)$ \\
\hline \multicolumn{2}{|l|}{ Number of comorbidities } \\
\hline$\geq 2$ & $56(93.3)$ \\
\hline$<2$ & $4(6.7)$ \\
\hline \multicolumn{2}{|l|}{ Type of comorbidity* } \\
\hline Malignancy & $60(100)$ \\
\hline Respiratory insufficiency & $51(85)$ \\
\hline Cardiovascular disease & $20(33.3)$ \\
\hline Chronic kidney disease & $16(26.7)$ \\
\hline Liver disease & $7(11.7)$ \\
\hline Diabetes mellitus & $2(3.3)$ \\
\hline
\end{tabular}

SD = standard deviation; SOFA = Sequential Organ Failure Assessment; $H A P=$ hospital-acquired pneumonia; $I A I=$ intra-abdominal infection; $C A P$ = community-acquired pneumonia; $U T I=$ urinary tract infection; HCAP = healthcare-associated pneumonia. "Percentages do not add up to $100 \%$ as some patients may have had more than one comorbidity.
The diagnosis of sepsis and septic shock were based on international criteria. ${ }^{1}$ Data were collected from the patients' medical and drug-prescribing records using a predesigned structured form. This included the patients' demographic characteristics, diagnosis, length of stay (LOS), Sequential Organ Failure Assessment (SOFA) score, the presence of co-morbidities (i.e. malignancy, diabetes mellitus, cardiovascular disease, chronic kidney disease, liver disease or respiratory insufficiency), source of infection, ventilator use, causative pathogens, antibiotic usage (i.e. type and dose), the timing of the specimen collection for culture and outcome. In addition, samples of blood, sputum, bronchial rinse and urine were collected for cultures and antimicrobial sensitivity testing.

Antibiotics were assessed for appropriateness according to type and dosage. Local microbial patterns during the period of June to December 2016 in the ICU were used to determine antimicrobial susceptibility data. ${ }^{9}$ The type of antibiotic prescribed during the study period was subsequently deemed appropriate if it was prescribed empirically according to the local microbial susceptibility data, whereas it was deemed to be inappropriate if it did not reflect the susceptibility data. This assessment was undertaken by the Antibiotic Stewardship Committee of the hospital, consisting of physicians, clinical pharmacists and nurses. Additionally, the appropriateness of each type of antibiotic was considered in light of the source of infection, as determined by the attending physician [Table 1]. ${ }^{17-20}$ The initial dose of the antibiotic was deemed appropriate after adjustment for the patient's clinical condition, while unadjusted dosages were considered inappropriate..$^{21}$

Data were analysed using the Statistical Package for the Social Sciences (SPSS), Version 23.0 (IBM Corp., Armonk, New York, USA). The independent variable was the appropriateness of the antibiotics (according to dose and type) and the dependent variable was patient outcome. Other variables included age, gender, diagnosis, number of comorbidities, ventilator use and SOFA score. Differences in the appropriateness of antibiotics based on local microbial patterns were presented as descriptive data, while differences in the appropriateness of antibiotics based on the source of infection and dosage were presented as both descriptive and analytical data. A corrected Chi-squared test was used to determine if the differences were significant. All correlations with a $P$ value of $<0.250$ were included in a subsequent multivariate analysis. A logistic regression analysis was performed to identify factors influencing patient outcome. A $P$ value of $<0.050$ was considered statistically significant.

Ethical approval for this study was obtained from the Ethical Committee of Dharmais Cancer Hospital (\#013/KEPK/II/2017). No patient consent was deemed necessary as permission to review the medical records was granted by the appropriate authorities at Dharmais 


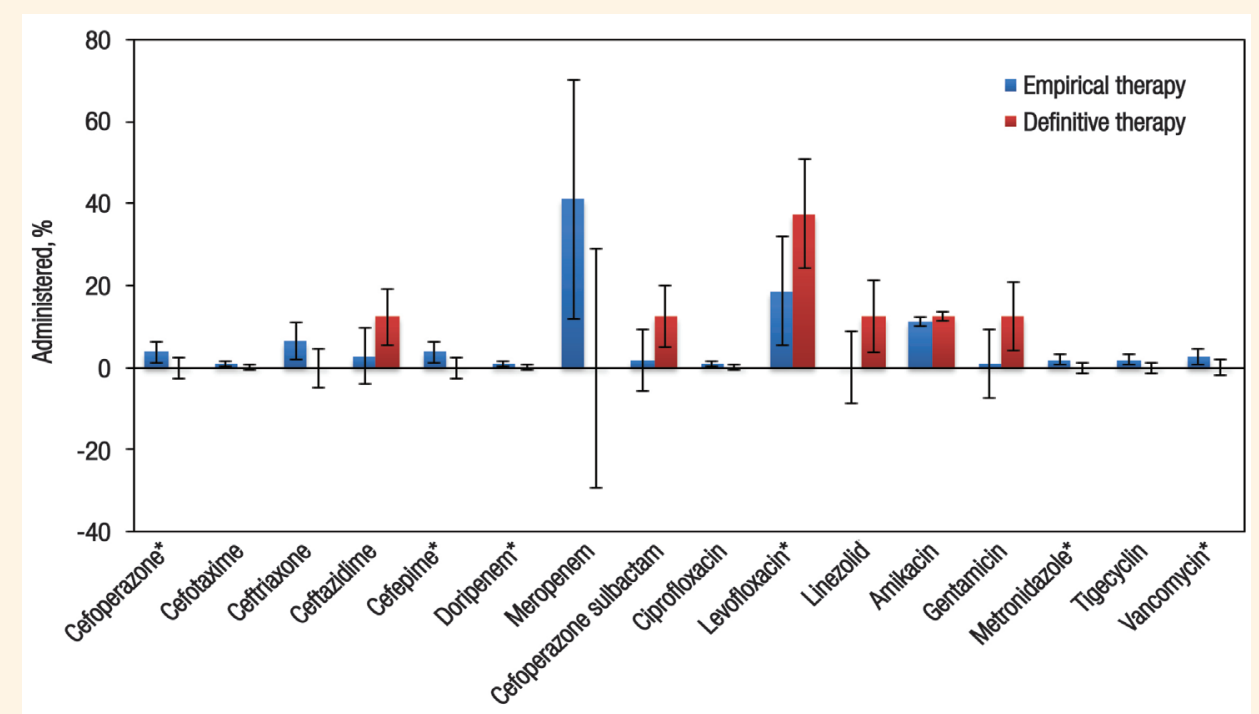

Figure 1: Distribution of empirical and definitive antibiotic regimens prescribed to sepsis patients admitted to the intensive care unit of Dharmais Cancer Hospital, Jakarta, Indonesia.

"Inappropriate according to local microbial patterns/antimicrobial susceptibility data.

Table 3: Correlations between appropriateness of type and dose of antibiotics and outcome among sepsis patients admitted to the intensive care unit of Dharmais Cancer Hospital, Jakarta, Indonesia $(\mathrm{N}=60)$

\begin{tabular}{|c|c|c|c|c|}
\hline \multirow[t]{2}{*}{ Variables } & \multicolumn{3}{|c|}{ n (\%) } & \multirow{2}{*}{$\begin{array}{c}P \\
\text { value }^{*}\end{array}$} \\
\hline & Total & $\begin{array}{c}\text { Died } \\
(\mathrm{n}=41)\end{array}$ & $\begin{array}{c}\text { Survived } \\
(\mathbf{n}=19)\end{array}$ & \\
\hline \multicolumn{5}{|c|}{ Type of antibiotic } \\
\hline Inappropriate & $20(33.3)$ & $17(85)$ & $3(15)$ & 0.050 \\
\hline Appropriate & $40(66.7)$ & $24(60)$ & $16(40)$ & \\
\hline \multicolumn{5}{|c|}{ Dose of antibiotic } \\
\hline Inappropriate & $31(51.7)$ & $25(80.6)$ & $6(19.4)$ & 0.034 \\
\hline Appropriate & $29(48.3)$ & $16(55.2)$ & $13(44.4)$ & \\
\hline
\end{tabular}

"Using a Chi-squared test.

Cancer Hospital. All information obtained during the review of the records was kept confidential and used only for the purposes of this study.

\section{Results}

A total of 182 patients were admitted to the ICU of Dharmais Cancer Hospital during the study period. Of these, 60 adults (33\%) were diagnosed with either sepsis (51.7\%) or septic shock (48.3\%). The mean age of the patients was $51.4 \pm 11.7$ years (range: $24-82$ years old) and $53.3 \%$ were male. The median LOS was $4.0 \pm 4.4$ days (range: $2-23$ days), with $80 \%$ staying less than seven days. Most patients had a SOFA score of $\leq 8$ (51.7\%) and used a ventilator (86.7\%). The most common source of infection was hospital-acquired pneumonia (HAP; 61.7\%), followed by intra-abdominal infections (IAI; 18.3\%).
Almost all of the patients had two or more comorbidities (93.3\%), with the most frequent being malignancy (100\%) and respiratory insufficiency (85\%) [Table 2].

Blood, sputum, bronchial rinse and urine samples were available for 49 patients (81.7\%). A total of 66 cultures were taken from the samples, of which 44 (66.7\%) were positive and $22(33.3 \%)$ were negative. Overall, 21 microorganisms were detected in the positive cultures, the most common being Acinetobacter baumannii (15.2\%), followed by Escherichia coli (6.1\%), Klebsiella pneumoniae (4.6\%) and Staphylococcus haemolyticus (4.6\%). Of the isolates from positive cultures, 41 (93.2\%) were known to be susceptible to antibiotics, while the remaining three (6.8\%) contained only fungi. In total, $39.3 \%$ of the microorganisms were resistant to the antibiotic administered, $28.6 \%$ were sensitive to the antibiotic administered, $4.8 \%$ had intermediate resistance to the antibiotic administered or required a higher dose and 27.4\% were not tested for sensitivity. Pseudomonas aeruginosa was the most sensitive to the administered antibiotics (87.5\%), while A. baumannii was the most resistant (72.2\%).

In total, there were 115 different antibiotic regimens, of which eight (7\%) constituted definitive therapy and 107 (93\%) were empirical. A total of 16 antibiotics were prescribed. Meropenem (41.1\%) was most frequently prescribed, followed by levofloxacin (20\%) and amikacin (11.3\%). Levofloxacin was prescribed in three of the definitive regimens (37.5\%) [Figure 1]. The most common antibiotic regimens consisted of meropenem (16\% in HAP cases, $40 \%$ in community-acquired pneumonia (CAP) cases, $50 \%$ in IAI cases and $33.3 \%$ in cases wherein the source of infection was unknown), meropenem plus levofloxacin (26\% in HAP cases, $40 \%$ in 
Table 4: Correlations between risk factors and outcome among sepsis patients admitted to the intensive care unit of Dharmais Cancer Hospital, Jakarta, Indonesia $(\mathrm{N}=60)$

\begin{tabular}{|c|c|c|c|c|}
\hline \multirow[t]{2}{*}{ Risk factor } & \multicolumn{3}{|c|}{ n (\%) } & \multirow{2}{*}{$\begin{array}{c}P \\
\text { value }\end{array}$} \\
\hline & Total & $\begin{array}{l}\text { Died } \\
(n=41)\end{array}$ & $\begin{array}{l}\text { Survived } \\
(\mathbf{n}=19)\end{array}$ & \\
\hline \multicolumn{5}{|l|}{ Age in years } \\
\hline$\geq 60$ & $12(20)$ & $9(75)$ & $3(25)$ & \multirow{2}{*}{0.579} \\
\hline$<60$ & $48(80)$ & $32(66.7)$ & $16(33.3)$ & \\
\hline \multicolumn{5}{|l|}{ Gender } \\
\hline Male & $32(53.3)$ & $23(71.9)$ & $9(28.1)$ & \multirow{2}{*}{0.528} \\
\hline Female & $28(46.7)$ & $18(64.3)$ & $10(35.7)$ & \\
\hline \multicolumn{5}{|l|}{ Diagnosis } \\
\hline Sepsis & $31(51.7)$ & $15(48.4)$ & $16(51.6)$ & \multirow{2}{*}{0.001} \\
\hline Septic shock & $29(48.3)$ & $26(89.7)$ & $3(10.3)$ & \\
\hline \multicolumn{5}{|l|}{ Ventilator use } \\
\hline Yes & $52(86.7)$ & $37(71.2)$ & $15(28.8)$ & \multirow{2}{*}{0.231} \\
\hline No & $8(13.3)$ & $4(50)$ & $4(50)$ & \\
\hline \multicolumn{5}{|l|}{ SOFA score } \\
\hline$>8$ & $29(48.3)$ & $25(86.2)$ & $4(13.8)$ & \multirow{2}{*}{0.004} \\
\hline$\leq 8$ & $31(51.7)$ & $16(51.6)$ & $15(48.4)$ & \\
\hline \multicolumn{5}{|c|}{ Number of comorbidities } \\
\hline$\geq 2$ & $56(93.3)$ & $40(71.4)$ & $16(28.6)$ & \multirow{2}{*}{0.054} \\
\hline$<2$ & $4(6.7)$ & $1(25)$ & $3(75)$ & \\
\hline \multicolumn{5}{|c|}{ Type of comorbidity } \\
\hline Malignancy & $60(100)$ & $41(68.3)$ & $19(31.7)$ & - \\
\hline $\begin{array}{l}\text { Respiratory } \\
\text { insufficiency }\end{array}$ & $51(85)$ & $36(70.6)$ & $15(29.4)$ & 0.371 \\
\hline $\begin{array}{l}\text { Cardiovascular } \\
\text { disease }\end{array}$ & $20(33.3)$ & $15(75)$ & $5(25)$ & 0.432 \\
\hline $\begin{array}{l}\text { Chronic } \\
\text { kidney disease }\end{array}$ & $16(26.7)$ & $12(75)$ & $4(25)$ & 0.503 \\
\hline Liver disease & $7(11.7)$ & $7(100)$ & $0(0)$ & 0.055 \\
\hline $\begin{array}{l}\text { Diabetes } \\
\text { mellitus }\end{array}$ & $2(3.3)$ & $2(100)$ & $0(0)$ & 0.327 \\
\hline
\end{tabular}

CAP cases and $14.3 \%$ in IAI cases), cefepime plus amikacin (100\% in healthcare-associated pneumonia cases), cefotaxime and ceftriaxone plus levofloxacin (50\% each in urinary tract infection cases). Overall, 23 patients (38.3\%) received one antibiotic, $26(43.3 \%)$ received two antibiotics, four (6.7\%) received three antibiotics, five (8.3\%) received four antibiotics and two (3.3\%) received five antibiotics.

A total of 20 patients (33.3\%) received inappropriate types of antibiotics according to either local microbial
Table 5: Multivariate analysis showing correlations between risk factors and outcome of sepsis patients in the intensive care unit of Dharmais Cancer Hospital, Jakarta, Indonesia $(\mathrm{N}=60)$

\begin{tabular}{|c|c|c|c|}
\hline Factors & & OR $(95 \% \mathrm{CI})$ & $P$ value \\
\hline Step 1 & Septic shock & $0.064(0.007-0.573)$ & 0.014 \\
\hline & $\begin{array}{l}\text { Presence of liver } \\
\text { disease }\end{array}$ & 0.000 & 0.999 \\
\hline & Ventilator use & $0.485(0.050-4.706)$ & 0.533 \\
\hline & $\begin{array}{l}\text { SOFA score } \\
\text { of }>8\end{array}$ & $0.295(0.066-1.310)$ & 0.108 \\
\hline & $\geq 2$ comorbidities & $0.042(0.002-1.018)$ & 0.051 \\
\hline & Constant & 78.297 & 0.015 \\
\hline Step 2 & Septic shock & $0.063(0.007-0.561)$ & 0.013 \\
\hline & $\begin{array}{l}\text { Presence of liver } \\
\text { disease }\end{array}$ & 0.000 & 0.999 \\
\hline & $\begin{array}{l}\text { SOFA score } \\
\text { of }>8\end{array}$ & $0.294(0.067-1.290)$ & 0.105 \\
\hline & $\geq 2$ comorbidities & $0.033(0.001-0.786)$ & 0.035 \\
\hline & Constant & 51.619 & 0.018 \\
\hline Step 3 & Septic shock & $0.048(0.006-0.411)$ & 0.006 \\
\hline & $\begin{array}{l}\text { SOFA score } \\
\quad \text { of }>8\end{array}$ & $0.251(0.060-1.053)$ & 0.059 \\
\hline & $\geq 2$ comorbidities & $0.023(0.001-0.556)$ & 0.020 \\
\hline & Constant & 71.819 & 0.012 \\
\hline
\end{tabular}

$O R=$ odds ratio; $C I=$ confidence interval; SOFA = Sequential Organ Failure Assessment.

*Using a logistic regression test.

patterns or the source of infection $(45.2 \%$ and $25 \%$, respectively). Inappropriate doses of antibiotics were prescribed to 31 patients (51.7\%), with dose adjustments required by 16 patients $(26.7 \%)$. The mortality rate was $68.3 \%$. There was a statistically significant positive association between patient outcome and inappropriate doses of antibiotics $(P=0.034)$, but not inappropriate types of antibiotics $(P=0.050)$ [Table 3]. According to a bivariate analysis, a diagnosis of septic shock, having at least two comorbidities, ventilator use, a SOFA score of $>8$ and the presence of a liver disorder had an effect on mortality $(P<0.250$ each) [Table 4$]$. A multivariate analysis indicated that a diagnosis of septic shock and the presence of at least two comorbidities were significantly associated with mortality $(P<0.050$ each $)$ [Table 5].

\section{Discussion}

In the current study, sepsis was more common among patients under 60 years old, although the mortality rate was higher among those over 60 years old. In the USA, the risk of sepsis increases with every 
year of age by $1.5 \% .^{22}$ Increased age over 60 years is a predictor of mortality in sepsis, particularly if adequate empirical antibiotic therapy is not initiated. ${ }^{23}$ In terms of gender, there were slightly more male than female patients in the current study. However, the frequency of sepsis among male patients was higher in a similar study conducted by Ferrer et al. (61.9\%). ${ }^{24}$ Adrie et al. demonstrated that older men are more vulnerable to sepsis than women. ${ }^{25}$ Another study showed that cross-linked mutations or polymorphisms in female mice resulted in the more dynamic activation, regulation and function of immune cells during the inflammatory process, while male mice only demonstrated a partial response to inflammation. ${ }^{26}$

Unfortunately, the mortality rate of patients with septic shock in ICUs remains high, despite fluid resuscitation measures, adequate care and the early administration of empirical antibiotics. ${ }^{27}$ In the current study, a diagnosis of septic shock was significantly associated with mortality, despite septic shock being less common. In a similar study, Ogura et al. reported that $45.2 \%$ of Japanese patients were diagnosed with septic shock, with a significantly higher mortality rate in this group (63.6\% versus $37.5 \% ; P<0.010) .{ }^{28}$ In sepsis, venodilation, fluid transudation from the vesicular space into the tissues, decreased oral intake and increased fluid loss facilitates the occurrence of hypovolaemic events; in septic shock, ventricular dysfunction and arteriolar dilatation contribute to the failure of function and organ perfusion. ${ }^{27}$ HAP is one of the most frequent and severe complications observed among patients hospitalised in ICUs. ${ }^{29}$ In the current study, HAP was the most frequent source of infection. However, Katu et al. found CAP to be most common among sepsis patients in a referral hospital in Indonesia. ${ }^{14}$ This could be due to differences in the location of the study, the sample and incidence of infections, as well as the extent of each individual patient's immune response.

Empirical antibiotic therapy is key in the initial management of sepsis patients. The type of antibiotic to be prescribed is usually determined by an assessment of the potential pathogens responsible for the infection, taking into account local antibiotic susceptibility patterns. ${ }^{30}$ However, failure to determine the source of infection can potentially lead to the misidentification of pathogens, resulting in the inappropriate selection of antibiotics. ${ }^{8,9}$ Previous research has established that the administration of inappropriate antimicrobials substantially increases mortality among sepsis patients. ${ }^{8,11-13}$ In the current study, a significant association was noted between inappropriate doses of antibiotics and mortality; however, there was no significant association between inappropriate types of antibiotics and mortality. In contrast, Katu et al. found that inappropriate types of antibiotics were significantly associated with mortality. ${ }^{14}$ This variation in results may again be due to differences in the sample as well as study design, such as the inclusion and exclusion criteria and antibiotic guidelines used. Nevertheless, the multivariate analysis in the present study indicated that the most significant factors associated with mortality were septic shock and the presence of at least two comorbidities; therefore, regardless of the appropriateness of the antibiotics administered, the mortality rate was still high. This is likely due to the critical clinical condition of such patients, which is generally poor in light of their admission to the ICU.

According to international guidelines, it is strongly recommended that appropriate antimicrobial therapy be administered within one hour of recognising cases of sepsis or septic shock. ${ }^{8}$ However, the exact antibiotic delivery time in the current study could not be assessed as almost all of the patients had received antibiotics prior to their admission to the ICU. Furthermore, antimicrobial sensitivity testing was not performed for all of the antibiotics administered during the study period due to interdepartmental miscommunication, wherein staff of the microbiology laboratory were unaware of the specific antibiotics being administered to sepsis patients in the ICU. Additionally, as the Antibiotic Stewardship Committee was still under development during this time, no uniform reference was available for the selection of antibiotics by hospital staff. Finally, microbial cultures could not be performed in 11 cases due to difficulties collecting samples from these patients.

\section{Conclusion}

This study found that inappropriate doses of antibiotics were significantly associated with mortality among sepsis patients in an Indonesian ICU, although inappropriate types of antibiotics were not. Furthermore, a diagnosis of septic shock and the presence of at least two comorbidities were significant risk factors related to mortality.

\section{CONFLICT OF INTEREST}

The authors declare no conflicts of interest.

\section{FUNDING}

No funding was received for this study.

\section{References}

1. Singer M, Deutschman CS, Seymour CW, Shankar-Hari M, Annane D, Bauer M, et al. The third international consensus definitions for sepsis and septic shock (Sepsis-3). JAMA 2016; 316:801-10. doi: 10.1001/jama.2016.0287. 
2. International Sepsis Forum. Promoting a better understanding of sepsis. From: http://internationalsepsisforum.com/wp-cont ent/uploads/2012/02/2003-revsion-Sepsis1103.pdf Accessed: May 2018.

3. Ullah AR, Hussain A, Ali I, Samad A, Ali Shah ST, Yousef M, et al. A prospective observational study assessing the outcome of sepsis in intensive care unit of a tertiary care hospital, Peshawar. Pak J Med Sci 2016; 32:688-93. doi: 10.12669/pjms.323.9978.

4. Fleischmann C, Scherag A, Adhikari NK, Hartog CS, Tsaganos T, Schlattmann P, et al. Assessment of global incidence and mortality of hospital-treated sepsis: Current estimates and limitations. Am J Respir Crit Care Med 2016; 193:259-72. doi: 10.1164/rccm. 201504-0781OC.

5. Ortíz G, Dueñas C, Rodríguez F, Barrera L, de La Rosa G, Dennis R, et al. Epidemiology of sepsis in Colombian intensive care units. Biomedica 2014; 34:40-7. doi: 10.1590/S0120-41572014000100007.

6. Kaukonen KM, Bailey M, Suzuki S, Pilcher D, Bellomo R. Mortality related to severe sepsis and septic shock among critically ill patients in Australia and New Zealand, 2000-2012. JAMA 2014; 311:1308-16. doi: 10.1001/jama.2014.2637.

7. Bochud PY, Glauser MP, Calandra T; International Sepsis Forum. Antibiotics in sepsis. Intensive Care Med 2001; 27:S33-48. doi: $10.1007 / \mathrm{pl} 00003796$

8. Rhodes A, Evans LE, Alhazzani W, Levy MM, Antonelli M, Ferrer R, et al. Surviving sepsis campaign: International guidelines for management of sepsis and septic shock - 2016. Intensive Care Med 2017; 43:304-77. doi: 10.1007/s00134-017-4683-6.

9. Yunus L, Prihartono NA, Tobing DL. [Primary bloodstream infection related to central venous catheter in patient with cancer at Dharmais National Cancer Center year 2011-2012]. M.Sc. Thesis, 2013, University of Indonesia Library, Depok, Indonesia.

10. Erbay A, Bodur H, Akinci E, Colpan A. Evaluation of antibiotic use in intensive care units of a tertiary care hospital in Turkey. J Hosp Infect 2005; 59:53-61. doi: 10.1016/j.jhin.2004.07.026.

11. Kumar A, Ellis P, Arabi Y, Roberts D, Light B, Parrillo JE, et al. Initiation of inappropriate antimicrobial therapy results in a fivefold reduction of survival in human septic shock. Chest 2009; 136:1237-48. doi: 10.1378/chest.09-0087.

12. Gaieski DF, Mikkelsen ME, Band RA, Pines JM, Massone R, Furia FF, et al. Impact of time to antibiotics on survival in patients with severe sepsis or septic shock in whom early goal-directed therapy was initiated in the emergency department. Crit Care Med 2010; 38:1045-53. doi: 10.1097/CCM.0b013e3181cc4824.

13. Lueangarun S, Leelarasamee A. Impact of inappropriate empiric antimicrobial therapy on mortality of septic patients with bacteremia: A retrospective study. Interdiscip Perspect Infect Dis 2012; 2012:765205. doi: 10.1155/2012/765205.

14. Katu S, Suwarto S, Pohan HT, Abdullah M. [Factors that influence the success of empirical antibiotic therapy in patients with severe sepsis and septic shock in the inpatient ward of the Hospital Cipto Mangunkusumo]. Indones Int Med J 2015; 2;96-106. doi: $10.7454 /$ jpdi.v2i2.72

15. Lwanga SK, Lemeshow S. Sample size determination in health studies: A practical manual. Geneva, Switzerland: World Health Organization, 1991. Pp. 1-26.

16. Anggriani Y, Banun A, Erliana. [Evaluation of antibiotic usage in HCU and ICU wards in Dharmais Cancer Hospital February to March 2012]. J Indones Pharm Sci 2013; 11:182-90.
17. Mandell LA, Wunderink RG, Anzueto A, BartlettJG, Campbell GD, Dean NC, et al. Infectious Diseases Society of America/American Thoracic Society consensus guidelines on the management of community-acquired pneumonia in adults. Clin Infect Dis 2007; 44:S27-72. doi: 10.1086/511159.

18. American Thoracic Society; Infectious Diseases Society of America. Guidelines for the management of adults with hospitalacquired, ventilator-associated, and healthcare-associated pneumonia. Am J Respir Crit Care Med 2005; 171:388-416. doi: 10.11 64/rccm.200405-644ST.

19. Mermel LA, Allon M, Bouza E, Craven DE, Flynn P, O'Grady NP, et al. Clinical practice guidelines for the diagnosis and management of intravascular catheter-related infection: 2009 Update by the Infectious Diseases Society of America. Clin Infect Dis 2009; 49:1-45. doi: 10.1086/599376.

20. Wagenlehner FM, Lichtenstern C, Rolfes C, Mayer K, Uhle F, Weidner W, et al. Diagnosis and management for urosepsis. Int J Urol 2013; 20:963-70. doi: 10.1111/iju.12200.

21. Lacy CF, Armstrong LL, Goldman MP, Leonard LL. Drug Information Handbook 2010-2011: A comprehensive resource for all clinicians and healthcare professionals, 19th ed. Hudson, Ohio, USA: Lexi-Comp Inc., 2010.

22. Martin GS, Mannino DM, Eaton S, Moss M. The epidemiology of sepsis in the United States from 1979 through 2000. N Engl J Med 2003; 348:1546-54. doi: 10.1056/nejmoa022139.

23. Nasa P, Juneja D, Singh O, Dang R, Arora V. Severe sepsis and its impact on outcome in elderly and very elderly patients admitted in intensive care unit. J Intensive Care Med 2012; 27:179-83. doi: $10.1177 / 0885066610397116$.

24. Ferrer R, Artigas A, Levy MM, Blanco J, González-Díaz G, Garnacho-Montero J, et al. Improvement in process of care and outcome after a multicenter severe sepsis educational program in Spain. JAMA 2008; 299:2294-303. doi: 10.1001/jama.299.19.2294.

25. Adrie C, Azoulay E, Francais A, Clec'h C, Darques L, Schwebel C, et al. Influence of gender on the outcome of severe sepsis: A reappraisal. Chest 2007; 132:1786-93. doi: 10.1378/chest.07-0420.

26. Chandra R, Federici S, Németh ZH, Horváth B, Pacher P, Haskó G, et al. Female X-chromosome mosaicism for NOX2 deficiency presents unique inflammatory phenotype and improves outcome in polymicrobial sepsis. J Immunol 2011; 186:6465-73. doi: 10.40 49/jimmunol.1100205.

27. Daniels R. Surviving the first hours in sepsis: Getting the basics right (an intensivist's perspective). J Antimicrob Chemother 2011; 66:ii11-23. doi: 10.1093/jac/dkq515.

28. Ogura H, Gando S, Saitoh D, Takeyama N, Kushimoto S, Fujishima S, et al. Epidemiology of severe sepsis in Japanese intensive care units: A prospective multicenter study. J Infect Chemother 2014; 20:157-62. doi: 10.1016/j.jiac.2013.07.006.

29. Imran M, Amjad A, Haidri FR. Frequency of hospital acquired pneumonia and its microbiological etiology in medical intensive care unit. Pak J Med Sci 2016; 32:823-6. doi: 10.12669/pjms. 324.8942 .

30. Fitousis K, Moore LJ, Hall J, Moore FA, Pass S. Evaluation ofempiric antibiotic use in surgical sepsis. Am J Surg 2010; 200:776-82. doi: 10.1016/j.amjsurg.2010.09.001. 